\title{
Cognitive-linguistic performance of schoolchildren in the literacy cycle in the public school context: universal screening
}

\author{
Angélica Galindo Carneiro Rosal ${ }^{1}$ \\ https://orcid.org/0000-0002-6937-8074
}

Ana Augusta de Andrade Cordeiro ${ }^{2}$ https://orcid.org/0000-0002-8458-3367

Antônio Roazzi

https://orcid.org/0000-0001-6411-2763

Bianca Arruda Manchester de Queiroga2

Universidade São Miguel - UnisãoMiguel; Departamento de Fonoaudiologia, Recife, Pernambuco, Brasil.

2 Universidade Federal de Pernambuco UFPE; Recife, Pernambuco, Brasil.

Research support source: Coordination for Higher Level Personnel Improvement (CAPES).

Conflict of interests: Nonexistent

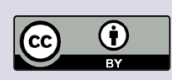

Received on: August 19, 2019

Accepted on: May 14, 2020

Corresponding address:

Angélica Galindo Carneiro Rosal Universidade Federal de Pernambuco -

Departamento de Fonoaudiologia

Avenida Professor Artur de Sá, s/n

Cidade Universitária

CEP: 50670-420 - Recife, Pernambuco,

Brasil

E-mail: angelicagalindo ufpe@hotmail.com angelicagalindocr@gmail.com

\section{ABSTRACT}

Objective: to characterize the linguistic-cognitive performance of schoolchildren in the literacy cycle, in order to identify children at risk for learning disorders in the public school context.

Methods: this study involved 88 children, aged 6 to 8 years, enrolled in the first, second and third year of elementary education I, from two schools in the city of Recife, Pernambuco, Brazil. The procedure used was the Cognitive-Linguistic Skills Evaluation Protocol, which has collective and individual versions, both being applied. The analysis of the groups was performed through the statistical non-parametric Kruskal-Wallis test with $p<0.05$.

Results: all students were submitted to the individual version for presenting poor performance in the collective version of the protocol. Thus, the application of the collective version was not sufficient to identify children at risk for learning disorders, thus, the indication of the individual assessment. In the individual version, students from the $1^{\text {st }}$ year showed a lower performance in most of the subtests that make up the instrument, whereas those from the $2^{\text {nd }}$ and $3^{\text {rd }}$ years had an average performance, which also deserves attention, according to the instrument of evaluation. These results, below the one expected for the age and school year, may be a consequence of poor learning opportunities within and outside school. There were also significant differences as a function of the schooling advance, revealing that the cognitive-linguistic skills, precursors of the reading and writing learning process, are only having a greater leap of development at the end of the literacy cycle, in the third year, which reveals a significant delay in terms of learning.

Conclusion: the low performance observed in cognitive-linguistic abilities in schoolchildren hinders the early identification of children at risk for learning disorders and questions the quality of educational opportunities experienced by the students inside and outside the public school. Other factors, such as regional differences in language and linguistic context, need to be considered in the interpretation of tests that evaluate cognitive-linguistic abilities.

Keywords: Learning; Cognition; Language; Learning Disorder 


\section{INTRODUCTION}

The Brazilian educational scenario of the past 20 years has shown a large number of students with low academic performance. The students' performance is assessed through external (International) ${ }^{1}$ and internal (national) evaluations ${ }^{2}$. The last external evaluation performed by the Program for International Student Assessment (PISA), conducted in 2015, showed that Brazilian students occupied, in mathematics, the $65^{\text {th }}$ position; in reading, the $59^{\text {th }}$ position; and, in sciences, the $63^{\text {rd }}$ position. These data are worrying, because Brazil is very poorly positioned between the 72 participating countries ${ }^{1}$.

Regarding the Literacy National Assessment (ANA), performed with students from public schools in the $3^{\text {rd }}$ year of elementary education I, the recent results revealed that $54.73 \%$ of them are at the lowest level of reading; $34 \%$ presented poor writing; and $54 \%$ did not have adequate knowledge in mathematics ${ }^{2}$. This low performance remains in the subsequent stages, as shown by the assessments of elementary education I and secondary education, lasting until the end of the basic education. It is important to highlight that the basic skills of reading and writing should be consolidated since the literacy ${ }^{3}$.

Due to the importance of the period of literacy, studies have focused on understanding the difficulties inherent to this educational step ${ }^{4,5}$. The literacy cycle comprises the $1^{\text {st }}, 2^{\text {nd }}$ and $3^{\text {rd }}$ year of elementary education, and aims to alphabetize, in the perspective of literacy, schoolchildren until 8 years of age, ensuring their right to learning ${ }^{6}$.

The low student performance in literacy cycle can occur due to extrinsic factors, mainly by the absence of good educational opportunities offered both by the family and by the school, which causes the so-called "learning difficulties", and intrinsic, which are the problems of biological nature, such as sensory deficits or neurological problems that cause the "learning disorders" $", 5$.

Thus, the main difficulties of students with learning disorders are those related to the cognitive-linguistic skills, such as difficulties in learning the alphabet, numbers, colors, days of the week and forms; difficulties in learning to write their own name; recite child verses or rhymes; segmenting words; reading words and pseudo words; difficulty to learn the relationship between grapheme-phoneme; among others ${ }^{7}$.

The schoolchildren at risk for learning disorders present performance below the expected for their group-class in the points considered prerequisites for a good performance in reading, such as the cognitivelinguistic abilities ${ }^{8}$. Therefore, they must be recognized early, because, the sooner they are identified, the lesser will be the difficulties related to the processes of teaching and learning, minimizing the risk for learning disorders ${ }^{9}$.

In Brazil, there is a lack of validated instruments that may be sensitive to identifying the risk for learning disorders. One of the instruments used for this purpose is the Cognitive-Linguistic Skills Evaluation Protocol - CLEP, which involves the skills of reading, writing, visual processing, auditory processing and metalanguage. This has been used for the universal screening of children at risk for learning disorders ${ }^{10}$ and applied in Brazilian studies ${ }^{5,11,12}$ based on the model of Response to Intervention (RTI) which is intended to students who have learning and behavioral difficulties, and requiring more specific interventions.

Therefore, the evaluation of those skills is indispensable, since changes in the cognitive-linguistic performance can influence the perception of speech segments and the recognition of elements necessary for the formation and identification of words ${ }^{13,14}$. Therefore, the objective of this study was to characterize the cognitive-linguistic performance of schoolchildren in the literacy cycle, in order to identify children at risk for learning disorders in the public school context.

\section{METHODS}

This research was approved by the Human Research Ethics Committee of the Health Sciences Center (CCS) of the Federal University of Pernambuco, Brazil, under opinion 091268/2015 CAAE n. 49097915.5.0000.5208 of the National Health Council.

The methodological path indicated for the present study prioritized a quantitative analysis, being the study characterized as descriptive, correlational and cross-sectional.

\section{Participants}

The sample was composed of 88 schoolchildren, being $54(61 \%)$ females and $34(39 \%)$ males, with age ranging from 6:0 to $8: 11$ years, enrolled in the $1^{\text {st }}, 2^{\text {nd }}$ and $3^{\text {rd }}$ year of elementary education, literacy cycle. The participants were distributed by age: $1^{\text {st }}$ year $(6$ years), $2^{\text {nd }}$ year ( 7 years), and $3^{\text {rd }}$ year (8 years), with no significant differences between the ages. 
The participants were enrolled in two public schools located in the Metropolitan Region of Recife (MRR), in the state of Pernambuco, Brazil. Both schools belong to the same neighborhood and are situated in the same administrative-politic region. According to the portal of the city of Recife, the neighborhood has a population predominantly parda or black $(68.04 \%)$, with a mean monthly income per household next to a minimum wage, which characterizes a population with low income ${ }^{15}$.

The selection of participants was carried out through the convenience sampling technique. The inclusion criteria were being enrolled in the school literacy cycle without the diagnosis of disability according to the school records.

Exclusion criteria included the absence of signing of the Informed Consent Form - ICF by parents and/ or guardians of the participants, students with any syndromic and/or neurological disorder, as well as sensory changes such as severe hearing and/or visual problems.

\section{Instruments}

\section{Cognitive-Linguistic Skills Evaluation Protocol - CLEP}

This instrument is validated and indicated to schoolchildren in the $1^{\text {st }}$ year to the $5^{\text {th }}$ year of basic education I. The purpose of this test is to evaluate different aspects of cognitive-linguistic processing of schoolchildren in phase of literacy, assisting in the identification of students with performance below expectations in reading and writing, in relation to their group-class. Once identified these children, it becomes possible to initiate the individualized investigation and even intervention with students with delayed skills of reading in the school context, even before referring to health professionals ${ }^{10}$.

The protocol has two versions: individual and collective.

The collective version is composed of five subtests: Writing of the alphabet in sequence; Copy of forms; mathematical calculation; writing under dictation of words; writing under dictation of pseudo words; and repeating numbers in random order.

In the analysis of the test, students whose performance is below their group-class or performance below the score should be submitted to the individual version. In this study, all students were submitted to the individual version since they had poor performance.
The individual version consists of thirteen subtests that evaluate: reading of words hits and time; reading of pseudo; alliteration; rhyme; repetition of words; repetition of pseudo words; rhythm; syllabic segmentation; rapid naming of figures; rapid naming of digits; visual memory for shapes; discrimination of sounds; and repeating numbers in reverse order.

The individual evaluations were performed in a room, more quietly as possible, with an approximate duration of 30 to 40 minutes, within their own educational institution, during the regular school period, being recorded and registered in their respective protocols for answers.

\section{Procedures}

The data were collected in the period from April to September 2016. Initially, individual data were obtained from the student's identification form in the school to get in contact with the parents. The parents or legal guardians received an information letter, containing the study objectives and ensuring the confidentiality of participants. Those who agreed to participate signed the Informed Consent Form - ICF. Subsequently, the schoolchildren were grouped according to the schooling, thus applying the evaluation instrument.

\section{Data analysis}

The analysis of cognitive-linguistic variables was performed according to the number of hits in the CLEP. The analysis of the score was classified into three categories: superior performance (SP), average performance (AP) and low performance (LP), considering the number of hits of the subtests of each test.

The comparison of the medians between the series was performed through a nonparametric test of Kruskal Wallis, which enables the comparison of three or more groups.

The data were examined through the Similarity Structure Analysis (SSA). The SSA is a non-metric form of multidimensional scaling analyses based on the Facet Theory, which is a procedure of theoretical research. It provides a framework of formal reference that facilitates the development of theories and hypotheses, uses methods that require a minimum of restrictions statistics and inter-relates the systematic research design, data collection and statistical analysis ${ }^{16}$.

This analysis processes a correlation matrix between $n$ variables, producing a geometric representation 
of the data, capable of reliably demonstrating the relationship between all the variables studied. In this way, the variables are represented graphically as points in a space, allowing checking the existence of relational structures, since the location of the points in this space will determine its relationship with the other points, i.e., with the other variables. In this way, the higher the correlation between two variables, the closer the points will be on the map and vice-versa ${ }^{16,17}$.

\section{RESULTS}

Table 1 shows the performance of the participants from the three years investigated in the collective version of the CLEP.

Table 1. Distribution of the results related to the cognitive-linguistic performance in the collective version by year of schooling, in schoolchildren in the $1^{\text {st }}, 2^{\text {nd }}$ and $3^{\text {rd }}$ years of the Elementary Education I, Recife, PE, Brazil, 2019. $(\mathrm{N}=88)$

\begin{tabular}{|c|c|c|c|c|c|c|c|c|c|c|c|}
\hline \multirow{2}{*}{ Variables } & \multirow{2}{*}{ Ref. } & \multicolumn{3}{|c|}{$1^{\text {st }}$ year } & \multicolumn{3}{|c|}{$2^{\text {nd }}$ year } & \multicolumn{3}{|c|}{$3^{\text {rd }}$ year } & \multirow{2}{*}{ p } \\
\hline & & Max & Min & Md & Max & Min & Md & Max & Min & Md & \\
\hline AlpWri & 26 & 26 & 9 & $10(1.5 ; 22.5)$ & 26 & 22 & $24(9.0 ; 26.0)$ & 26 & 7 & $26(7.0 ; 26.0)$ & $.013^{\star}$ \\
\hline CopF & 4 & 4 & 0 & $1(0.0 ; 3.0)$ & 2 & 0 & $1(0.0 ; 2.0)$ & 4 & 2 & $3(2.0 ; 3.0)$ & $.001^{*}$ \\
\hline Mat & 20 & 1 & 0 & $0(0.0 ; 0.0)$ & 3 & 1 & $0(0.0 ; 1.0)$ & 12 & 0 & $3(1.0 ; 8.5)$ & $.001^{*}$ \\
\hline WorDic & 30 & 17 & 0 & $0(0.0 ; 0.0)$ & 13 & 2 & $0(0.0 ; 5.25)$ & 28 & 2 & $7(0.0 ; 21.0)$ & $.001 *$ \\
\hline PseDic & 10 & 4 & 0 & $0(0.0 ; 0.0)$ & 3 & 0 & $0(0.0 ; 1.0)$ & 8 & 0 & $1(0.0 ; 5.0)$ & $.001 *$ \\
\hline RNAle & 10 & 5 & 0 & $1(0.0 ; 3.0)$ & 10 & 0 & $0(0.0 ; 4.0)$ & 10 & 7 & $9(7.0 ; 10.0)$ & $.001^{*}$ \\
\hline
\end{tabular}

* Kruskal-Wallis test, comparing the three years, adopting a $5 \%$ significance level $\left(p={ }^{\star} 0.050\right)$.

Legend: Ref.: maximum possible score on the administered subtest; Max: maximum score of hits; Min: minimum score of hits; Md: median (Q1; Q3). AlpWri: alphabet writing in sequence; CopF: copy of forms; Mat: mathematical calculation; WorDic: writing under word dictation; PseDic: written under pseudo word dictation; RNAle: repetition of numbers in a random order.

The results show that there was no significant difference between the year at all skills investigated. Despite the difference in the collective version, participants of the $1^{\text {st }}$ year obtained a lower performance in all the subtests evaluated, students in the $2^{\text {nd }}$ year also showed lower performance in the subtests, with the exception of writing the alphabet, which had average performance. The students from the $3^{\text {rd }}$ year showed superior performance in writing the alphabet and random repetition of numbers, average performance in the copy of figures and lower performance in the others.

Table 2 reveals the analysis of the score, which allows classifying the performances of the participants in superior, average or low in the collective version of the CLEP.

Table 2. Classification of the cognitive-linguistic performance of schoolchildren in the collective version

\begin{tabular}{lcccccc}
\hline Variables & SP & AP & LP & 1st $^{\text {year Median }}$ & $\mathbf{2}^{\text {nd }}$ year Median & 3 $^{\text {rd }}$ year Median \\
\hline AlpWri & 26 & $13-24$ & 12 & $10(1.5 ; 22.5)$ & $24(9.0 ; 26.0)$ & $26(7.0 ; 26.0)$ \\
CopF & 4 & $2-3$ & 1 & $1(0.0 ; 3.0)$ & $1(0.0 ; 2.0)$ & $3(2.0 ; 3.0)$ \\
Mat & $16-20$ & $10-15$ & $0-9$ & $0(0.0 ; 0.0)$ & $0(0.0 ; 1.0)$ & $3(1.0 ; 8.5)$ \\
WorDic & $25-30$ & $15-24$ & $0-14$ & $0(0.0 ; 0.0)$ & $0(0.0 ; 5.25)$ & $7(0.0 ; 21.0)$ \\
PseDic & $8-10$ & $5-7$ & $0-4$ & $0(0.0 ; 0.0)$ & $0(0.0 ; 1.0)$ & $1(0.0 ; 5.0)$ \\
RNAle & $2-6$ & $2-4$ & $2-3$ & $1(0.0 ; 3.0)$ & $0(0.0 ; 4.0)$ & $9(7.0 ; 10.0)$ \\
\hline
\end{tabular}

Legend: AlpWri: alphabet writing in sequence; CopF: copy of forms; Mat: mathematical calculation; WorDic: writing under word dictation; PseDic: written under pseudo word dictation; RNAle: repetition of numbers in a random order; SP: superior performance - child's limit of hits; AP: average performance - characterized by around $50 \%$ of the total score; LP: low performance - below $50 \%$ of the total score. 
As possible to observe, despite the significant differences presented in function of the advancement of education, students have lower performance in tasks of mathematical calculation, dictation of words and pseudo words, according to the classification of the protocol. In this way, the collective version of the instrument was not sensitive for identifying students with higher learning difficulties, i.e., children at risk for learning disorders. For this reason, as already described in the chapter of method, all participants were submitted to the individual version of the test. The performance of all participants in the individual version of CLEP can be observed in Table 3.

Table 3. Distribution of the results related to the cognitive-linguistic performance in the individual version by year of schooling, in schoolchildren in the $1^{\text {st }}, 2^{\text {nd }}$ and $3^{\text {rd }}$ years of the Elementary Education I, Recife, PE, Brazil, 2019. $(\mathrm{N}=88)$

\begin{tabular}{|c|c|c|c|c|c|c|c|c|c|c|c|}
\hline \multirow{2}{*}{ Variables } & \multirow{2}{*}{ Ref. } & \multicolumn{3}{|c|}{ 1st year } & \multicolumn{3}{|c|}{ 2nd year } & \multicolumn{3}{|c|}{3 rd year } & \multirow[b]{2}{*}{ p } \\
\hline & & Max & Min & Md & Max & Min & Md & Max & Min & Md & \\
\hline Rea. Wor. & 70 & 27 & 8 & $6(2.0 ; 18.75)$ & 20 & 7 & $9(4.5 ; 19.5)$ & 70 & 4 & $\begin{array}{c}42.5 \\
(23.0 ; 66.75)\end{array}$ & $.002^{*}$ \\
\hline Rea. Pseu. & 10 & 10 & 8 & $2(1.25 ; 4.74)$ & 10 & 3 & $7.5(2.75 ; 10.0)$ & 10 & 5 & $10(7.0 ; 10.0)$ & $.001^{*}$ \\
\hline Aliter & 10 & 10 & 0 & $3(0.5 ; 5.0)$ & 10 & 5 & $6(4.5 ; 10.0)$ & 10 & 1 & $6(4.0 ; 7.0)$ & $.020^{*}$ \\
\hline Rhyme & 20 & 19 & 15 & $12(6.0 ; 15.0)$ & 20 & 14 & $19(13.5 ; 19.5)$ & 20 & 3 & $14(10.5 ; 18.0)$ & $.039^{*}$ \\
\hline Rep. Wor. & 8 & 5 & 4 & $4(3.0 ; 4.0)$ & 7 & 5 & $4(2.75 ; 5.25)$ & 6 & 2 & $4(4.0 ; 5.0)$ & $.007^{*}$ \\
\hline Rep. Pseu. & 7 & 4 & 3 & $3(2.0 ; 3.0)$ & 4 & 2 & $3.5(2.0 ; 4.0)$ & 4 & 3 & $3(3.0 ; 4.0)$ & .085 \\
\hline Rhythm & 12 & 5 & 3 & $3(2.0 ; 3.0)$ & 7 & 3 & $3(2.0 ; 4.5)$ & 6 & 2 & $4(3.0 ; 4.0)$ & $.013^{*}$ \\
\hline Syl. Segm. & 20 & 20 & 16 & $13(11.0 ; 16.0)$ & 20 & 17 & $14.5(10.0 ; 17.5)$ & 20 & 9 & $18(13.0 ; 20.0)$ & $.008^{*}$ \\
\hline RNS Fig. & 60 & 46 & 34 & $55(4.0 ; 66.5)$ & 45 & 33 & $\begin{array}{c}45.5 \\
(41.75 ; 64.75)\end{array}$ & 58 & 25 & $40(34.0 ; 48.0)$ & $.000^{*}$ \\
\hline RNS Dig. & 60 & 57 & 37 & $61(53.5 ; 90.5)$ & 66 & 43 & $63(47.0 ; 81.25)$ & 58 & 25 & $\begin{array}{c}39.5 \\
(31.75 ; 60.25)\end{array}$ & $.001^{*}$ \\
\hline $\begin{array}{l}\text { Visu. } \\
\text { Memo. }\end{array}$ & 8 & 5 & 0 & $2(1.0 ; 4.0)$ & 7 & 0 & $3(1.0 ; 4.5)$ & 6 & 0 & $4(2.5 ; 5.0)$ & $.007^{*}$ \\
\hline Disc. Sou. & 20 & 20 & 17 & $18(14.5 ; 20.0)$ & 20 & 11 & $18.5(17.0 ; 19.0)$ & 20 & 10 & $17(13.0 ; 20.0)$ & .718 \\
\hline RNRev. & 10 & 5 & 0 & $2(2.0 ; 3.0)$ & 5 & 2 & $2.5(1.25 ; 4.0)$ & 5 & 0 & $1(1.0 ; 1.0)$ & .779 \\
\hline
\end{tabular}

* Kruskal-Wallis test, comparing the three years, adopting a $5 \%$ significance level $\left(p={ }^{*} 0.050\right)$.

Legend: Ref.: maximum possible score on the administered subtest; Max: maximum score of hits; Min: minimum score of hits; Md: median (Q1; Q3). Rea. Wor:: reading of words; Pseu. Wor:: reading of pseudo words; Aliter.: alliteration; Rhyme: rhyme; Rep. Wor:: repetition of words; Rep. Pseu.: repetition of pseudo words; Rhythm: rhythm; Syl. Segm.: syllabic segmentation; RNS Fig.: rapid naming of figures (time); RNS Dig.: rapid naming of digits (time); Visu. Memo.: visual memory for forms; Disc. Sou.: discrimination of sounds; RNRe: repetition of numbers in a reverse order.

The results in the individual version shows a significant difference between the years in the skills of reading words and pseudo-words, alliteration, rhyme, repetition of words and pseudo words, syllabic segmentation, rhythm, rapid naming of figures and digits, and visual memory for shapes, showing an improvement in performance as schooling increases.

The analysis of the score of the performance of the participants of the three years investigated in the individual version of CLEP can be observed in Table 4.

The data indicate that participants in the $1^{\text {st }}$ year obtained superior performance in the discrimination of sounds and rapid naming of figures. In $2^{\text {nd }}$ year, there was also a superior performance in these skills, in addition to others, such as rhyme and repetition of pseudo words. The students from the $3^{\text {rd }}$ year showed superior performance in reading pseudo syllabic segmentation, and rapid naming of figures and digits.

As seen, the rapid naming of figures was the only one in which all participants obtained superior performance. On the other hand, the repetition of numbers in reverse order was the most difficult task, because all groups showed lower performance. In general, students in the $1^{\text {st }}$ year showed lower performance in most of the subtests, the schoolchildren in the $2^{\text {nd }}$ and $3^{\text {rd }}$ years had average performance, which also deserves attention in accordance with the evaluation instrument.

Considering the results described above and with the objective of verifying the behavior of all the variables investigated, in both individual and collective versions of the CLEP, depending on the educational advances, 
Table 4. Classification of the cognitive-linguistic performance of schoolchildren in the individual version

\begin{tabular}{|c|c|c|c|c|c|c|}
\hline \multirow{2}{*}{ Variables } & \multirow{2}{*}{ SP } & \multirow{2}{*}{ AP } & \multirow{2}{*}{ LP } & $1^{\text {st }}$ year & $2^{\text {nd }}$ year & $3^{\text {rd }}$ year \\
\hline & & & & Median & Median & Median \\
\hline Rea. Wor. & $60-70$ & $30-59$ & $0-29$ & $6(2.0 ; 18.75)$ & $9(4.5 ; 19.5)$ & $42.5(23.0 ; 66.75)$ \\
\hline Rea. Pseu. & $8-10$ & $5-7$ & $0-4$ & $2(1.25 ; 4.74)$ & $7.5(2.75 ; 10.0)$ & $10(7.0 ; 10.0)$ \\
\hline Aliter & $8-10$ & $5-7$ & $0-4$ & $3(0.5 ; 5.0)$ & $6(4.5 ; 10.0)$ & $6(4.0 ; 7.0)$ \\
\hline Rhyme & $18-20$ & $7-17$ & $0-6$ & $12(6.0 ; 15.0)$ & $19(13.5 ; 19.5)$ & $14(10.5 ; 18.0)$ \\
\hline Rep. Wor. & $2-5$ & $2-4$ & 2 & $4(3.0 ; 4.0)$ & $4(2.75 ; 5.25)$ & $4(4.0 ; 5.0)$ \\
\hline Rep. Pseu. & $2-4$ & $2-3$ & 2 & $3(2.0 ; 3.0)$ & $3.5(2.0 ; 4.0)$ & $3(3.0 ; 4.0)$ \\
\hline Rhythm & $8-12$ & $4-7$ & $0-3$ & $3(2.0 ; 3.0)$ & $3(2.0 ; 4.5)$ & $4(3.0 ; 4.0)$ \\
\hline Syl. Segm. & $18-20$ & $7-17$ & $0-6$ & $13(11.0 ; 16.0)$ & $14.5(10.0 ; 17.5)$ & $18(13.0 ; 20.0)$ \\
\hline RNS Fig. & $60 "$ & $60 "-90 "$ & $91 "$ & $55(4.0 ; 66.5)$ & $45.5(41.75 ; 64.75)$ & $40(34.0 ; 48.0)$ \\
\hline RNS Dig. & $60 "$ & 60"-90" & $91^{\prime \prime}$ & $61(53.5 ; 90.5)$ & $63(47.0 ; 81.25)$ & $39.5(31.75 ; 60.25)$ \\
\hline Visu. Memo. & $2-5$ & $2-4$ & 2 & $2(1.0 ; 4.0)$ & $3(1.0 ; 4.5)$ & $4(2.5 ; 5.0)$ \\
\hline Disc. Sou. & $18-20$ & $7-17$ & $0-6$ & $18(14.5 ; 20.0)$ & $18.5(17.0 ; 19.0)$ & $17(13.0 ; 20.0)$ \\
\hline RNRe. & $2-6$ & $2-4$ & 2 & $2(2.0 ; 3.0)$ & $2.5(1.25 ; 4.0)$ & $1(1.0 ; 1.0)$ \\
\hline
\end{tabular}

Legend: Rea. Wor.: reading of words; Time Rea. Pal.: time to read words; Pseu. Wor.: reading of pseudo words; Aliter.: alliteration; Rhyme: rhyme; Rep. Wor:: repetition of words; Rep. Pseu.: repetition of pseudo words; Rhythm: rhythm; Syl. Segm.: syllabic segmentation; RNS Fig.: rapid naming of figures (time); RNS Dig.: rapid naming of digits (time); Visu. Memo.: visual memory for forms; Disc. Sou.: discrimination of sounds; RNRe: repetition of numbers in a reverse order. SP: superior performance - child's limit of hits; AP: average performance - characterized by around $50 \%$ of the total score; LP: low performance - below $50 \%$ of the total score.

there is a need to carry out an exploratory analysis of the relationship between such skills and school grades.

Figure 1 illustrates the multidimensional scaling of the results, through the geometric representation of the data. There is a correlation between the 24 cognitive-linguistic variables studied in function of years of schooling. The similarities structure analysis (SSA) designed a polar structure differentiating into three facets/dimensions, with each facet revealing the proximity of variables with one school year.

The first facet, next to the $1^{\text {st }}$ year, projects the variables of rapid naming of digits and figures. These skills are thus placed because the values computed in the results refer to the processing speed (or the time spent in the naming), which was greater among schoolchildren in the $1^{\text {st }}$ year. In this way, despite being prepared in this facet, one should consider the distancing of the skills of the $3^{\text {rd }}$ year, which reveals a negative correlation in function of the schooling advance.

The second facet, next to the $2^{\text {nd }}$ year, projects the variables of discrimination of sounds, repetition of pseudo words and repetition of numbers, which showed no statistically significant differences between the years, in addition to being less than expected for the level of schooling in the three groups studied. In the case of repetition of numbers, the performance was near the bottom in the three groups and, in the case of discrimination of sounds, average performance, also in the three groups (Table 4). Although there was no statistically significant differences between the years, in these skills, the averages of the performance of the $2^{\text {nd }}$ year were a little higher than the other groups, which justifies the projection in this space.

The third facet contains the other variables, with greater proximity of $3^{\text {rd }}$ year, evidencing that the cognitive-linguistic abilities investigated, which are precursors of the learning process of reading and writing, are only having a greater leap of development at the end of the literacy cycle, which reveals a significant delay in terms of learning. Furthermore, the value of the alienation coefficient of the present study was lower than 0.15 , which is equivalent to a solution acceptable to interpret the data in the light of the SSA ${ }^{16,17}$. 


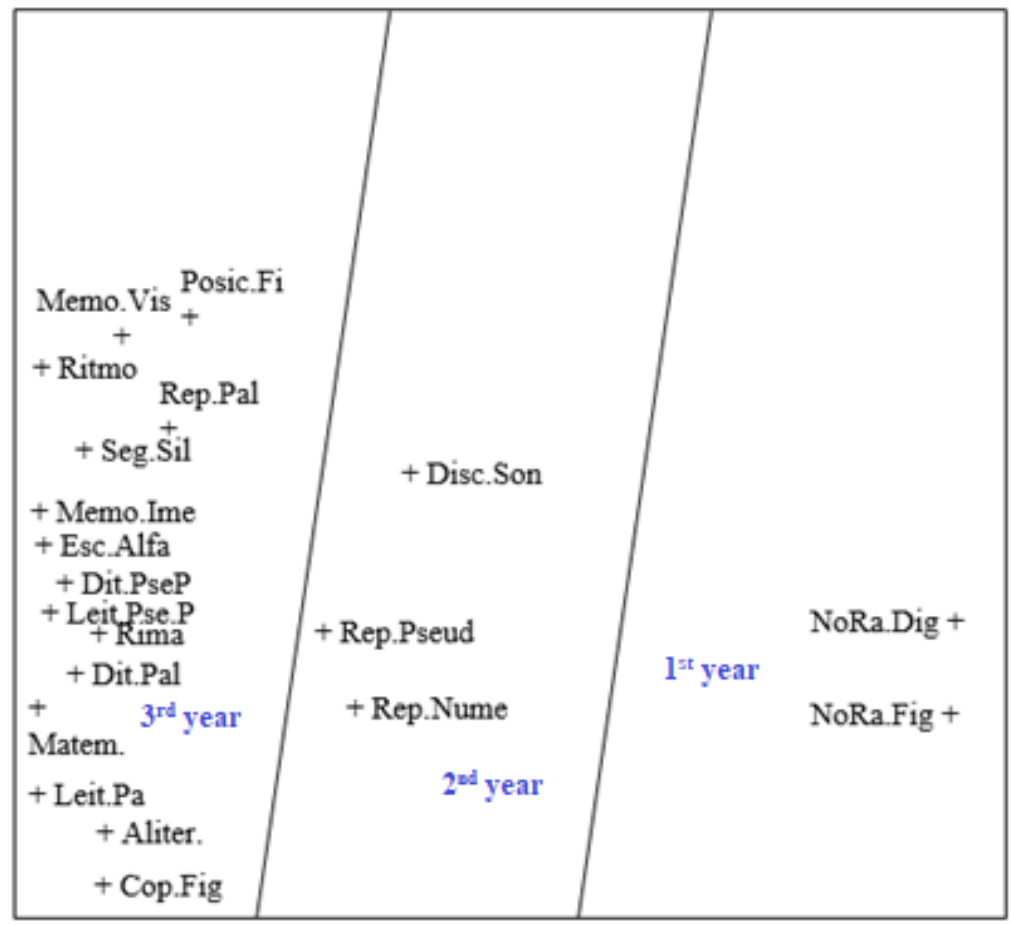

Legend: Esc.Alfa: alphabet writing in sequence; CopFig: copy of forms; Matem.: mathematical calculation; Dit.Pal: writing under word dictation; Dit.PseP: written under pseudo word dictation; Memo.Ime: repetition of numbers in random order; Leit.Pa.: word reading; Leit.Pseu.P: pseudo word reading; Aliter.: alliteration; Rima: rhyme; Rep.Pal.: repetition of words; Rep. Pseud.: repetition of pseudo words; Ritmo: rhythm; Seg.Sil.: syllabic segmentation; NoRa.Fig.: rapid naming of figures (time); NoRa. Dig.: rapid digit naming (time); Memo.Vis.: visual memory for shapes; Posic.Fig: figure positioning; Disc.Son.: discrimination of sounds; Rep.Nume: number repetition in a reverse order.

Figure 1. Similarity structure analysis of the categories produced regarding the accuracy in cognitive-linguistic performance, considering as external variables the three levels of education (3d, 1x2; Alienation Coefficient .13)

\section{DISCUSSION}

Overall, the results revealed that the schoolchildren were below the expected performance in cognitivelinguistic skills assessed through the collective and individual versions of the CLEP ${ }^{10}$. This low performance may have resulted from environmental factors that can interfere with learning, such as: economic aspects and social-educational opportunities, hindering distinguishing children with difficulties from those with learning disorders. Importantly, the learning occurs from the interaction between the biological conditions - nervous system and perceptual systems, and educational opportunities offered by the family and by the school ${ }^{18}$.

As part of the educational opportunities important to be experienced in the literacy cycle, there stands out the stimulation of cognitive-linguistic abilities, since they are essential to the acquisition of reading and writing ${ }^{13}$. These should be developed from the early childhood education, through programs of cognitive-linguistic development, allowing the students be more prepared to enter the literacy cycle ${ }^{5}$.
On the other hand, in spite of the low performance, when assessing the cognitive-linguistic abilities of students, there were significant differences between the years in function of the schooling advance, revealing that the schoolchildren in the $3^{\text {rd }}$ year of the literacy cycle presented advances in some skills when compared to children in the $1^{\text {st }}$ and $2^{\text {nd }}$ years. Therefore, there seems to be a significant delay in the acquisition of cognitive-linguistic skills and precursor of literacy in the population studied, which hinders identifying children at risk for learning disorders.

Similarly, a study ${ }^{13}$ assessed children in the $2^{\text {nd }}$ to $5^{\text {th }}$ years of basic education from the public network in order to perform an adaptation of a test of cognitive performance. The results showed significant differences in cognitive-linguistic abilities in function of schooling, but, in general, the schoolchildren exhibited difficulties in tasks of naming, visual memory, reversibility and phonological awareness regardless of the schooling.

Such findings make reflect on literacy. According to the National Pact for Literacy at the Right Age PNAIC ${ }^{6}$, all students should be literate until eight years 
of age, requiring the grasp of different knowledge and basic skills underlying the rights of learning, involving the reading, the production of written texts, orality and linguistic analysis. This suggests that the schoolchildren in the $1^{\text {st }}$ year of the literacy cycle should have the following competences: deepening of the reading and understanding of texts; introduction and intensification of production of written texts; use of diverse vocabularies; introduction of the relation of speech with writing; introduction and deepening of the use of spellings of words with regular direct correspondence between letters and phonemes; among other skills ${ }^{6}$.

Thus, when comparing the goals of learning proposed by PNAIC ${ }^{18}$ with the results of this study, the participants are much lower than expectations, and this difference may be related to the performance below the expected in cognitive-linguistic abilities.

It is important to highlight that two other studies ${ }^{5,19}$ were performed by applying the CLEP. The first study ${ }^{5}$ aimed to investigate the cognitive-linguistic profile of students with difficulties in the acquisition of written language. The participants were 45 students enrolled in the $2^{\text {nd }}$ year of elementary education I, divided in control group (without learning difficulties) and at-risk group (with learning difficulties). All of them were evaluated with the collective and individual versions. The schoolchildren in the at-risk group presented lower performance than the control group in the skills of reading and writing and phonological processing. The authors concluded that the intervention programs should consider the cognitive-linguistic abilities, especially the phonological processing, which is directly connected with the school learning.

In the second study ${ }^{19}$, the authors compared the applicability of an intervention program in schoolchildren with risk for reading difficulties. They drafted a phonological program for 20 students identified as at risk for reading difficulties, aged 6 to 7 years and 11 months, enrolled in the $1^{\text {st }}$ and $2^{\text {nd }}$ year of elementary education I. The results unveiled that the students at risk had a significant improvement in naming letters, grapheme-phoneme relation, phonological awareness, phonological working memory, reading and writing.

The results of studies ${ }^{5,19}$, if compared to the present study, demonstrated that, even the students considered at risk for learning disorders presented better results in the collective and individual versions of the test that the participants of this study. This can be explained by the fact that these surveys occurred in the Southeastern region, whose sociocultural context is different from the Northeastern region, which shows the importance of considering the socio-demographic profile and opportunities of the population investigated for a better understanding of the results. Another fact to emphasize is that CLEP does not make clear the demographic profile of the population evaluated in the step of validation of the instrument, which could also justify such differences.

The literature indicates that the geographical location in isolation does not interfere in the performance of schoolchildren, but the educational opportunities. A survey conducted in the Northeastern region ${ }^{11}$ aimed to analyze the cognitive-linguistic performance of schoolchildren in the early years of elementary education I. The participants were students enrolled in the $2^{\text {nd }}$ and $3^{\text {rd }}$ years of elementary education I, from a private school in Campina Grande - PB.

The results of the individual version of CLEP indicated that the students reached the highest performance in the reading of words and pseudo words, syllabic segmentation, discrimination of sounds and repetition of non-words. In other skills, the level of the performance of the sample was considered moderate. The students in the $3^{\text {rd }}$ year showed superior performance in the reading skills of words and pseudo words and writing skills, if compared to the participants in the $2^{\text {nd }}$ year, which indicates the relation between these skills and school progression. There was an increase in the average of hits in the subtests of the ability of phonological awareness, indicating a possible stabilization of these skills at this level of education ${ }^{11}$.

Therefore, it is possible to verify that the participants of that study, by the end of the literacy cycle, seem to stabilize the phonological abilities, unlike the present study, which showed a lag of those skills throughout the educational cycle. Thus, despite having been performed in the same region, the students of the state of Paraíba, Brazil, were enrolled in a school of the private network, which suggests better educational opportunities.

The performance of students who are studying in private schools, in general, is better than that of the students from the public network, because there is greater participation of parents in the academic life of the child, accompanying his/her development and encouraging the learning process, as well as a greater concern on the part of the school with learning. These aspects favor the motivation and interest of the students, helping in school performance ${ }^{20}$. 
Corroborating the idea of the importance of the family for learning, a survey ${ }^{21}$ affirms that the family is one of the first environments of social construction of the subject, being responsible for the collective and individual experiences of the child. In the family environment, the child learns to manage and resolve conflicts, to control the emotions, expressing the different feelings that constitute the interpersonal relations, to deal with the diversities and misfortunes of life.

Based on the above, and considering the different educational realities in which the Brazilian schoolchildren are inserted, the results of this study demonstrate the need for Brazilian studies consider the cultural aspects of the populations studied. Some studies $^{11,22,23}$ that investigated aspects related to the learning of reading and writing in schoolchildren in the Brazilian Northeast observed a lower trend of performances of schoolchildren when compared to the performances of studies performed in other regions. Therefore, it reinforces the importance of considering cultural factors and the linguistic context of the various Brazilian regions to establish reference values in national surveys.

Other aspects related to the performances in various skills assessed by the CLEP deserve to be highlighted. Regarding the performance of schoolchildren in the abilities of phonological processing, for example, among the phonological awareness tasks, students obtained better results in the subtests of syllabic segmentation than in the subtests of alliteration and rhyme. These results corroborate the findings of other studies ${ }^{5,24}$ that also reported the initial development of the syllabic segmentation in comparison to other activities of phonological processing, due to the degree of complexity of sound processing required in the different activities.

Regarding the processing speed, in the present study, all schoolchildren exhibited superior performance in the abilities of rapid naming of figures. In the rapid naming of numbers, the performance of students was classified as moderate in the $1^{\text {st }}$ and $2^{\text {nd }}$ years and superior in the $3^{\text {rd }}$ year. According to the literature ${ }^{22,25}$, the rapid naming is directly related to the experiences of students' reading, and its development favors the increasingly rapid and automatic recovery of the word, which suggests that the schoolchildren with difficulties to identify and decode words may present with changes in the storage and retrieval of information.
The difficulties in the storage and retrieval of information can be observed in the subtest of visual memory. In this study, the students in the $1^{\text {st }}$ year showed lower performance, and the $2^{\text {nd }}$ and $3^{\text {rd }}$ years had average performance. These results deserve special attention, because children at risk for learning disorders have difficulties in tests that require the storage of information, which may be explained by the fact that a possible impaired visual processing leads to a change in the storage of information, which leads to a low performance in tests of that level ${ }^{26}$.

The present study also revealed difficulties in the abilities of auditory processing, especially in the task of rhythm. These results indicate the difficulties of schoolchildren in audibly processing the information, making use of the auditory memory and auditory perception, responsible for receiving and interpreting the sounds or words received ${ }^{27}$.

\section{CONCLUSION}

In general, the schoolchildren obtained a cognitivelinguistic performance below expectations for their schooling and this low performance can be explained by external factors, especially by the educational opportunities, regional and linguistic context, which need to be considered in situations of screening, evaluation and diagnosis of learning difficulties.

These factors hinder the early identification of children at risk for learning disorders in the context of public schools and reveal the importance of developing assessment tools considering the sociodemographic factors and social-educational opportunities, as well as specific programs for intervention and monitoring of learning of those students.

The results of this study suggest the need for developing evaluation strategies and intervention towards pre-school children, in order to prepare them for the stage of the literacy cycle, thereby improving the quality of education in public schools, since the beginning of formal schooling.

\section{REFERENCES}

1. OCDE. PISA 2015. Technical Report. 2013. Versão eletrônica. Disponível em: http://www.oecd.org/ pisa/ . Acesso em: 19 fev. 2018.

2. Brasil. ANA - Avaliação Nacional da Alfabetização. Brasília: INEP, [S.d.], 2016a. Disponível em: http:// portal.inep.gov.br/educacao-basica/saeb/sobrea-ana Acesso em: 15 fev. 2018. 
3. Navas ALGP. Por que prevenir é melhor que remediar quando se trata de dificuldades de aprendizagem. In: Alves LM, Mousinho R, Capellini SA (orgs). Dislexia: novos temas, novas perspectivas. Rio de Janeiro: Wak Editora. 2011, vl. p. 41-53.

4. Rodrigues SD, Ciasca SM. Dislexia na escola: identificação e possibilidades de intervenção. Rev. Psicopedag. 2016;33(100):86-97.

5. Andrade OVCA, Andrade PE, Capellini SA. Caracterização do perfil cognitivo-linguístico de escolares com dificuldades de leitura e escrita. Psicologia: Reflexão e Crítica [online], 2014 [Acesso em 25 de junho de 2017]; 27 2):358-67. Disponível em: www.redalyc.org/html/188/18831347018/

6. Brasil. Ministério da Educação. Portaria № 826, de 7 de Julho de 2017. Pacto Nacional pela Alfabetização na Idade Certa. Disponível em: http:// pacto.mec.gov.br/images/pdf/legislacao/portaria_ mec_826_alterada.pdf Acesso em: 10 set. 2017.

7. Silva NSD, Silva FJAD. A dislexia e a dificuldade na aprendizagem. Revista Científica Multidisciplinar [online], 2016 [Acesso em 17 de agosto de 2019]; 5(1):75-87. Disponível em: https:// www.nucleodoconhecimento.com.br/saude/ dislexia-dificuldade-aprendizagem

8. Mayeda GBG, Navatta ACR, Miotto EC. Phonologic intervention in school kids on risk of dyslexia: Literature review. Rev. Psicopedag. 2018;35(107):231-41.

9. Nascimento IS, Rosal AGC, Queiroga BAM. Elementary school teachers' knowledge on dyslexia. Rev. CEFAC [online] 2018 [Acesso em 17 de março de 2019]; 20(1):87-94. Disponível em doi: 10.1590/1982-021620182019117

10. Capellini AS, Smythe I, Silva C. Protocolo de avaliação de habilidades cognitivo-linguísticas. Livro do profissional e do professor. Marília: Fundepe. 2012.

11. Melo MRA. Análise multidimensional do desempenho cognitivo-linguístico de escolares dos anos iniciais do ensino fundamental: atualizações a partir da Teoria das Facetas [Tese]. Recife (PE): Universidade Federal de Pernambuco; 2013.

12. Antunes LG, Freire T, Crenitte PAP. Phonological awareness training in students with risk indicators for learning difficulties. Distúrb. Comum. 2015;27(2):225-36.

13. Capellini SA, Silva C, Gonzaga J, Galhardo MT, Cruvinel P, Smythe I. Desempenho cognitivo: linguístico de escolares de $1^{1^{a}}$ a $4^{a}$ séries do ensino público municipal. Rev. Psicopedag. [online] 2007 [Acesso em 15 de junho de 2017];24(73):30-44. Disponível em: pepsic.bvsalud.org/pdf/psicoped/ v24n73/v24n73a05.pdf

14. Germano GD, César ABP, Capellini SA. Protocolo de triagem para identificação precoce de crianças brasileiras em risco de dislexia. Front. Psychol. [online] 2017 [Acesso em 20 de julho de 2019]; 8:1763. Disponível em: http://hdl.handle. net/11449/170328

15. Prefeitura do Recife. Perfil dos bairros. Disponível em: http://www2.recife.pe.gov.br/ servico/mangueira?op $=\mathrm{NzQ} 0 M Q==$. Acesso em: 04 fev. 2020.

16. Bilsky W. A teoria das facetas: noções básicas. Estudos de Psicologia. 2003;8(3):357-65.

17. Roazzi A, Souza BC, Bilsky W. Facet Theory: searching for structure in complex social, cultural and psychological phenomena. Recife: Editora Universitária da UFPE [online] 2015 [Acesso em 15 de junho de 2017]. Disponível em: https://goo.gl/ p48ywC .

18. Grossi MGR, Lopes AM, Couto PA. A neurociência na formação de professores: um estudo da realidade brasileira. Rev Faeeba [online] 2014 [Acesso em 15 de novembro de 2017]; 23(41):27-40. Disponível em: https://revistas.uneb. br/index.php/faeeba/article/viewFile/821/579 /

19. Silva NSM, Crenitte PAP. Efficacy of phonological intervention program in students at risk for dyslexia. Rev. CEFAC [online] 2015 [Acesso em 10 de junho de 2017]; 17(6):1827-37. Disponível em: http:// dx.doi.org/10.1590/1982-021620151760215

20. Lima ES. A "qualidade" da educação no Brasil: escola pública $X$ escola particular. Universidade da Bahia. Bahia. 2006. Disponível em: http://www. webartigos.com/artigos Acesso em: 03 jan. 2017.

21. Dessen MA, Polonia AC. A Família e a escola como contextos de desenvolvimento humano. Paidéia. 2007;17(36):21-32.

22. Rosal AGC, Cordeiro AAA, Silva ACF, Silva RL, Queiroga BAM. Contributions of phonological awareness and rapid serial naming for initial learning of writing. Rev. CEFAC [online] 2016 [Acesso em 04 de fevereiro de 2018];18(1):74-85. Disponível em: doi: 10.1590/1982-0216201618110315

23. Silva ACF, Cordeiro AAA, Queiroga BAM, Rosal AGC, Carvalho EA, Roazzi A. Relation between phonological development and writing initial 
learning in different socio-educational settings Rev. CEFAC [online] 2015 [Acesso em 18 de outubro de 2017];17(4):1115-31. Disponível em: http://dx.doi. org/10.1590/1982-0216201517415214

24. Andrade OVCA, Andrade PE, Capellini SA. Collective screening tools for early identification of dyslexia. Front. Psychol. [online] 2015 [Acesso em 12 de junho de 2017]; 2(23):1-13. Disponível em: www.ncbi.nlm.nih.gov/pmc/articles/PMC4304252/ .

25. Silva C, Capellini, SA. Efficacy of phonological intervention program in students at risk for dyslexia. Rev. CEFAC [online] 2015 [Acesso em 02 de março de 2018]; 17(6):1827-37. Disponível em: https://doi. org/10.1590/1982-021620151760215

26. Medina GBK, Souza FF, Guimarães SRK. Funções executivas e leitura em crianças brasileiras com dislexia do desenvolvimento. Rev. Psicopedag. 2018;35(107):168-79.

27. Flor CM. Perfil cognitivo de uma criança com diagnóstico prévio da dislexia do desenvolvimento associada ao transtorno do processamento auditivo central: estudo de caso. Rev. Psicopedag. 2018;35(106):104-15.

\section{ERRATUM}

In the article, "Cognitive-linguistic performance of schoolchildren in the literacy cycle in the public school context: universal screening", with DOI number: $10.1590 / 1982-0216 / 20202239919$, published in the journal Revista Cefac 2020;22(3):e9919, in "Data analysis" (page 3):

\section{Where it was:}

\section{Reference 14}

The data were examined through the Similarity Structure Analysis (SSA). The SSA is a non-metric form of multidimensional scaling analyses based on the Facet Theory, which is a procedure of theoretical research. It provides a framework of formal reference that facilitates the development of theories and hypotheses, uses methods that require a minimum of restrictions statistics and inter-relates the systematic research design, data collection and statistical analysis ${ }^{14}$.

\section{Read:}

\section{Reference 16}

The data were examined through the Similarity Structure Analysis (SSA). The SSA is a non-metric form of multidimensional scaling analyses based on the Facet Theory, which is a procedure of theoretical research. It provides a framework of formal reference that facilitates the development of theories and hypotheses, uses methods that require a minimum of restrictions statistics and inter-relates the systematic research design, data collection and statistical analysis ${ }^{16}$. 